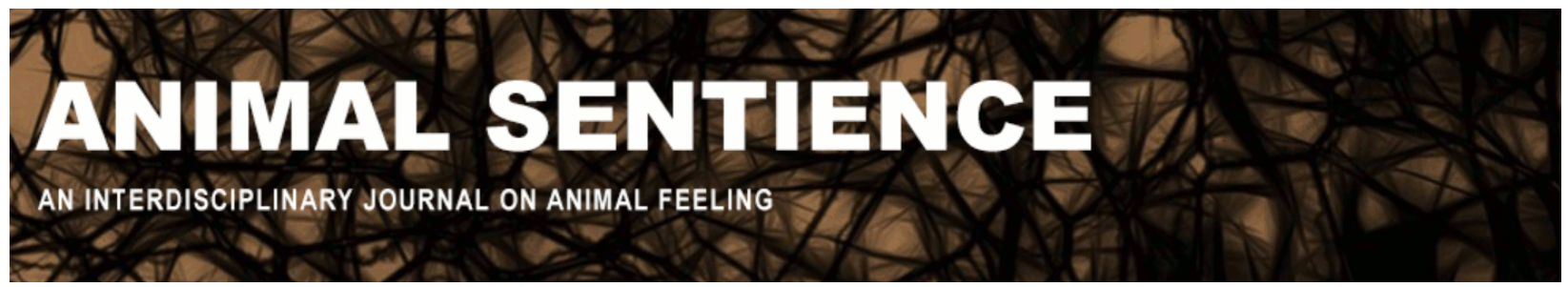

Jenni, Kathie (2017) Scientific advances and moral inertia. Animal Sentience 17(9)

DOI: $10.51291 / 2377-7478.1259$

Date of submission: 2017-11-19

Date of acceptance: 2017-11-29

(c) $\underset{\mathrm{EY}}{\mathrm{C}}$

This article has appeared in the journal Animal

Sentience, a peer-reviewed journal on animal

cognition and feeling. It has been made open access,

free for all, by WellBeing International and deposited

in the WBI Studies Repository. For more information,

please contact

wbisr-info@wellbeingintl.org.

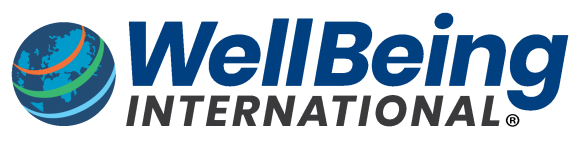

SOLUTIONS FOR PEOPLE, ANIMALS AND ENVIRONMENT 


\title{
Scientific advances and moral inertia
}

Commentary on Marino on Thinking Chickens

\author{
Kathie Jenni \\ Department of Philosophy \\ University of Redlands
}

\begin{abstract}
Marino shows that chickens are as complex mentally as other birds and mammals. Yet common perceptions of chickens are slow to change in response to the science. Human capacities for willful ignorance, inattention, and avoidance keep us from learning about the animals we harm, and the inertia of habit and tradition keeps us from taking appropriate action in response to what we learn. It's essential for teachers and activists to find ways to overcome this inattention and inertia.
\end{abstract}

Keywords: cognition, complexity, inattention, inertia, reform

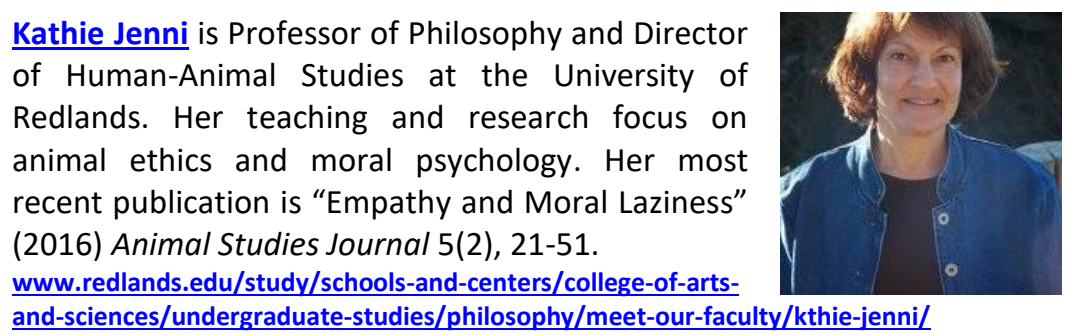

Lori Marino (2017a,b) provides a comprehensive and compelling review of chickens' mental lives. The evidence shows chickens are as complex cognitively, socially, and emotionally as other birds and mammals. Yet common perceptions of chickens are slow to change in response to the evidence. Indeed, Marino (2017b) notes, many people barely think of chickens as birds at all. This is partly because chickens, unlike most birds, are categorized as commodities (p. 127).

Marino's findings matter because many people are more willing to accept exploitation of simpler animals than of more complex ones. Chickens are among the most brutally abused animals in the world. This is not recognized as the moral catastrophe it is partly because chickens are misperceived as simple, comical, and stupid. Yet people who come to know them through personal contact discover that they are smart, emotional animals with individual personalities (Marino, 2017b, p. 128).

Marino suggests that the scientific community itself has been unduly influenced by common perceptions of chickens. Studies of adaptive avian specializations and of simpler abilities such as associative learning have focused on chickens and pigeons, whereas studies of processes such as language and tool use in birds have focused on corvids and parrots. This selective focus in research has prevented chickens from demonstrating their more complex capacities. Marino (2017b) suggests that in a vicious circle with devastating consequences, researchers' choice to focus on simpler abilities in chickens both reflects and reinforces the "disconnect" between what chickens are actually like and popular images of them (p. 128).

Marino's aims are to gain a better understanding of the minds of chickens from the research literature and to identify important areas for future noninvasive research. There is a 
case to be made against invasive animal research, on both moral and scientific grounds. Many scientists have not adequately grappled with it. (See Engel, 2012; Greek and Greek, 2000, 2004; Norcross, 2012; and Regan, 2004.) It is unusual and gratifying to hear noninvasiveness proposed by Marino as an explicit ethical boundary for future studies.

Marino's review shows that capacities once thought to be uniquely human, such as emotions, are present not just in chickens and other farmed animals, but throughout the animal kingdom. Personality traits, too, are common in other animals. Yet it is a daunting battle to use this knowledge to transform our practices. One hallmark of our species is our remarkably flexible capacity for willed ignorance, inattention, and self-deception, especially when inconvenient facts threaten treasured practices (Zentall, 2016). We also suffer from simple inertia, born of habit and tradition, that keeps us in the grip of prejudices about other animals long after they are shown to be unfounded. To make things worse, chickens are at an immense disadvantage compared to animals whose faces we can read, whom we find furry and attractive, and whose expressive vocalizations readily signal their pain and suffering to us. Marino's review shows that pigs share cognitive and emotional capacities with primates. Fish too have been shown to have complex capacities (Balcombe, 2016a,b); their suffering likewise goes unheeded.

The capacity for suffering and enjoyment alone should be enough to induce us to renounce causing animals harm. Yet the idea that animals must not only suffer but be smart to deserve protection is a common one. One step toward ending public support for factory farming and other atrocities is to make consumers aware of the mental capacity of the species we use. Marino (2017b) cites a study showing that college students who train and care for chickens come to change their views about them (p. 128). My experience has been that students who read moral arguments and descriptions of factory farming, view documentaries about the practice, and judge that it is wrong still struggle to make personal changes in their diets. Yet visiting a Farm Sanctuary, where they can physically interact with chickens, pigs, and cows in a calm and natural setting - where the animals can show their individual natures - can overcome years of inertia, uncertainty, and waffling. (But see Bottomley and Boughlan, 2017.)

Opportunities to interact with farmed animals are not available to the great majority of people in urban areas. Are there other ways to reach them? Perhaps chickens need an analogue to Blackfish (2013), which introduced an individual orca and conveyed his nature and story vividly enough to turn many people against captive orca shows, which in turn moved businesses like SeaWorld to change their practices.

Given the financial and political power of agribusiness, changing public policy is even tougher than changing public perceptions. Yet passage of Proposition 2 in California (2008) and similar initiatives in other states has shown that citizens care enough about animal cruelty to vote for reforms when given the chance. At the federal level, the Humane Methods of Slaughter Act excludes chickens and other birds from even the minimal protection of (supposedly) painless killing. Objective differences between birds and other farmed animals do not justify this exclusion; it is also unknown to most citizens and shocking to many when they learn it. Thus it would make a well-focused target for activist efforts at reform. The killing of male chicks in the egg industry by suffocating them in plastic bags or dumping them into giant grinders is a similar extreme: monstrously inhumane, concealed from the public, and a source of moral shock when it is witnessed. (Undercover footage of this practice is the one - and only - thing that elicits unguarded gasps from my students, who are otherwise savvy about factory farming practices 
and accustomed to disturbing film footage.) This, too, would make a powerful focus for efforts to change current practice.

Some activists (Francione, 2015; LaVeck, 2017) denigrate efforts to promote "humane farming" of animals, arguing that this simply enables those who eat animals to feel better, without ending the fundamental exploitation and disrespect for animals in agriculture. Thinkers are right to point out that it is fundamentally wrong to treat animals as mere resources (Regan, 2004), but it would also be wrong (and a betrayal of current victims) to abandon efforts to remedy the worst suffering of farmed animals. We can advocate for immediate reforms while seeking to put an end to animal agriculture altogether in the long run.

\section{References}

Balcombe, J. (2016a). What a fish knows: The inner lives of our underwater cousins. New York, NY: Scientific American/Farrar, Straus and Giroux.

Balcombe, J. (2016b). In praise of fishes: Précis of What a fish knows. Animal Sentience 8(1).

Bottomley, E. and Loughnan, S. (2017). Chickening out of change: Will knowing more about thinking chickens change public perceptions?. Animal Sentience 17(8).

Cowperthwaite, G. (2013). Blackfish. http://www.blackfishmovie.com. Dogwoof.

DeGrazia, D. (2002). Meat-Eating. In Animal rights: A very short introduction. Oxford: Oxford University Press.

Durand, A. (2009). Fowl play. Mercy for Animals.

Engel, M. (2012). The commonsense case against animal experimentation. In Garrett, J., The ethics of animal research: exploring the controversy. Cambridge, MA: The MIT Press. pp. 21536.

Francione, G. and Charlton, A. (2015). Animal rights: The abolitionist approach. Newark, NJ: Exempla Press.

Greek, C.R. and Greek, J.S. (2000). Sacred cows and golden geese: The human costs of experiments on animals. New York: Continuum.

Greek, C.R. and Greek, J.S. (2004). What will we do if we don't experiment on animals? Victoria, BC: Trafford.

Humane Methods of Slaughter Act. (1958/1978). United States Department of Agriculture. Jenni, K. (2003). Vices of inattention. Journal of Applied Philosophy 20(3), 279-295. Jenni, K. (2016). Empathy and moral laziness. Animal Studies Journal 5(2), 21-51.

LaVeck, J. and Stein, J. (2017). Humanemyth.org. http://www.humanemyth.org/toh.htm Accessed 11/25/2017.

Marino, L. (2017a). The inconvenient truth about thinking chickens. Animal Sentience 17(1).

Marino, L. (2017b). Thinking chickens: A review of cognition, emotion, and behavior in the domestic chicken. Animal Cognition 20: 127-147.

Norcross, A. (2012). Animal experimentation, marginal cases, and the significance of suffering. In Garrett, J., The ethics of animal research: Exploring the controversy. Cambridge, MA: The MIT Press. pp. 67-80.

Regan, T. (2004). The case for animal rights. 2nd edition. Berkeley: University of California Press.

Zentall, T.R. (2016). Cognitive dissonance or contrast? Animal Sentience 12(1). 